\title{
I 06 I The effect of Simpson's method and the Piecewise Smooth Subdivision Surface reconstruction method on right ventricle volume measurement and reconstruction
}

\author{
Teresa F Moroseos*1, David Sahn², Willem Helbing33, Alan Shurman ${ }^{4}$, \\ Harold Litt ${ }^{5}$ and Florence Sheehan ${ }^{1}$
}

\begin{abstract}
Address: ${ }^{1}$ University of Washington, Seattle, WA, USA, ${ }^{2}$ Oregon Health \& Science University, Portland, OR, USA, ${ }^{3}$ Erasmus Medical Center, Rotterdam, The Netherlands, ${ }^{4}$ Royal Brompton Hospital, London, UK and ${ }^{5}$ University of Pennsylvania, Philadelphia, PA, USA

* Corresponding author
\end{abstract}

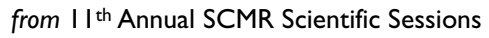

Los Angeles, CA, USA. I-3 February 2008

Published: 22 October 2008

Journal of Cardiovascular Magnetic Resonance 2008, I0(Suppl I):AI86 doi:I0.I I86/I532-429X-I0-SI-AI86

This abstract is available from: http://jcmr-online.com/content/I0/SI/AI86

(c) 2008 Moroseos et al; licensee BioMed Central Ltd.

\section{Background}

Magnetic resonance imaging (MRI) using Simpson's method is the gold standard for measuring RV volume. The Piecewise Smooth Subdivision Surface (PSSS) reconstruction method is the only method that has been validated for accuracy in reproducing the 3-D shape of a heart ventricle as well as for measuring ventricular volume. The 3-D shape of the RV in congenital heart disease patients is distorted at the base and apex, regions difficult to visualize from short axis views.

\section{Purpose}

We compared RV volume measured by Simpson's method and the PSSS reconstruction method.

\section{Methods}

We studied six normal patients and 18 patients whose RVs carry a systemic pressure load, half of whom had transposition of the great arteries (TGA) repaired with an atrial baffle and half with congenitally corrected TGA (ccTGA). Images acquired included a short axis stack, radially related long axis views, and oblique views intended to fully visualize the RV. The RV borders were manually traced and used to reconstruct the RV endocardial surface by the PSSS method, which produces a triangulated mesh. Volume was measured by summing the signed volumes of tetrahedra formed by connecting a point in space with each triangle on the mesh. The Simpson's analysis was performed on the short axis stacks alone, which were traced separately without reference to any other views.

\section{Results}

Each study group yielded smaller RV volumes when analyzed with Simpson's method as compared with PSSS reconstruction method. The normal patients showed a $5.8 \%$ decrease in RV volume size for ED and an $11.8 \%$ decrease in ES $(\mathrm{p}<0.020)$. Patients with ccTGA showed a $5.7 \%$ loss in volume in ED and a 9.6\% loss in ES ( $\mathrm{p}<$ 0.026 ). Congenital hearts with TGA displayed a $4.3 \%$ volume change in ED and $6.4 \%$ volume change in ES (p = NS).

\section{Conclusion}

When analyzed with Simpson's method, the RV volume was consistently smaller than the PSSS reconstructive method for normal hearts and hearts with ccTGA, but not in TGA. These differences may be attributable to the superior visualization of basal and apical structures from long axis views. Unlike the left ventricle, $\mathrm{RV}$ analysis should be performed with additional views due to the more complex shape of this chamber. 
Table I: Average RV volume and EF difference between Simpson's method and PSSS reconstructive method

\begin{tabular}{|c|c|c|c|c|c|c|c|c|c|}
\hline$D_{x}$ & EDV I* & EDV 2* & pl** & ESV I & ESV 2 & $\mathrm{p} 2 * *$ & EF I & EF 2 & p3** \\
\hline Normal & 156 & 147 & 0.015 & 76 & 67 & 0.020 & 52 & 54 & NS \\
\hline ccTGA & 265 & 250 & 0.018 & 197 & 178 & 0.026 & 33 & 34 & NS \\
\hline TGA & 231 & 221 & NS & 156 & 146 & NS & 28 & 29 & NS \\
\hline
\end{tabular}

$* \mathrm{I}=\mathrm{RV}$ Volume by PSSS Reconstructive Method $(\mathrm{mL}) ; 2$ = RV Volume by Simpson's method $(\mathrm{mL})$. ** $\mathrm{pl}=$ paired T-Test results between end diastolic volumes (EDV) of Simpson's and the PSSS method; $\mathrm{p} 2=$ paired T-Test results between end systolic volumes (ESV) of Simpson's and the PSSS method; $\mathrm{p} 3$ = paired T-Test results between EFs of Simpson's and the PSSS method.

Publish with Biomed Central and every scientist can read your work free of charge

"BioMed Central will be the most significant development for disseminating the results of biomedical research in our lifetime. "

Sir Paul Nurse, Cancer Research UK

Your research papers will be:

- available free of charge to the entire biomedical community

- peer reviewed and published immediately upon acceptance

- cited in PubMed and archived on PubMed Central

- yours - you keep the copyright 